\title{
Specific Air Pollution in Road Tunnels
}

\author{
R. Ličbinský*, J. Huzlík, A. Frýbort, J. Jedlička \\ Transport Research Centre, Brno, Czech Republic \\ *Corresponding author: roman.licbinsky@cdv.cz
}

K. Kreislová

SVÚOM Ltd., Prague, Czech Republic

DOI: $10.2478 / \mathrm{v} 10158-012-0037-9$

\begin{abstract}
Negative effects of air pollution are, apart from the adverse effects on human health, also associated with damaging material goods which is manifested in e.g. the shorter service life of construction materials and faster material corrosion. Road tunnel environment is very specific since the emissions of passing vehicles are not dispersed into the surroundings and materials in the tunnel are thus immediately exposed to the pollutants produced by traffic. This paper presents the first results of measurements of specific air pollution in road tunnels of the project No TA01031043 "Quantification of specific pollution effect on materials and corrosion protection in tunnels". The total concentration of nitrogen oxides was higher in the first sampling campaign. Nitrogen dioxide concentration was higher in the second sampling campaign that corresponds to a higher traffic intensity. $\mathrm{H}_{2} \mathrm{~S}$ and $\mathrm{SO}_{2}$ concentrations were almost similar in both campaigns. Higher $\mathrm{PM}_{2.5}$ concentrations were measured in the second sampling campaign that corresponds to higher traffic intensity associated with higher fine particle emissions from combustion processes. Lower $\mathrm{PM}_{10}$ concentrations in the second sampling campaign were measured probably due to the conversion of some particles to a gaseous phase due to a higher temperature and humidity. The concentrations of all measured pollutants were typically changed in between local minimal values and local maximum values in relation to daytime, or traffic volume, respectively. The particle size distribution showed in both campaigns a dominant share of coarse PM fraction $\mathrm{PM}_{2.5-10}$ but also its very high fluctuation in time. The highest share of coarse fraction was determined in the time of rush hours in the morning, as opposed to the lowest share during the night time.
\end{abstract}

KEYWORDS: Road tunnel, emission, nitrogen oxides, particulate matter.

\section{INTRODUCTION}

The negative effects of air pollution are, except for the adverse effects on human health, also associated with the damage of natural ecosystems, agricultural production and with the damage of material goods manifested in e.g. the shorter service life of construction materials and faster material corrosion. From this point of view, road tunnel environment is very specific since the emissions of passing vehicles are not dispersed to the surroundings and materials in the tunnel are thus immediately exposed to the pollutants produced by traffic which results in the fast degradation of materials, even those which should withstand these processes. 
Only several measurements of air pollution in road tunnel have been performed in the Czech Republic. Measurements by Czech Hydrometeorological Institute using a measuring vehicle in the Letenský tunnel was performed in 1992 and by TESO Praha a.s. in the Strahovský tunnel in 2009 (Velíšek, 2010). More attention has been paid to road tunnel environment in other countries. Air pollution was monitored in different types of road tunnels generally in order to characterize the emission production by vehicles and for subsequent calculations of emission factors of different pollutants, for validation of different numerical models or for the assessment of exposure of persons in passing vehicles. Measurements were performed in road tunnels that are a component of the main road network in different cities such as Gothenburg (Barrefors, 1996), Stockholm (Kristensson et al., 2004), Vilnius (Valiulis et al., 2002), Vienna (Handler et al., 2008), Lisbon (Oliveira et al., 2011), Antwerp (Worobiec et al., 2011), Pittsburgh (Greishop et al., 2006), Houston (McGaughey et al., 2004), New York City (Lonneman et al., 1986), Sao Paolo (Sánchez-Ccoyllo et al., 2009), Hong Kong (Ho et al., 2009). Air pollution monitoring was also performed in several highway tunnels such as the Lundby tunnel in Sweden, the Plabutsch tunnel in Austria, the Gubrist tunnel in Switzerland (Hausberger et al., 2003; Colberg et al., 2005), the Grand Mare tunnel in France (Gouriou et al., 2004), the Wutong tunnel in China (He et al., 2006) or the Hsueh-shan tunnel in Taiwan (Ma et al., 2011).

Very few studies deal with other aspects of tunnel environment, including possible degradation and corrosion of materials. Song et al. (2005) characterized dust accumulated on tunnel walls and roof in tunnels in Hong Kong and Guangzhou in China. Similarly Lésniewska et al. (2004) analysed dust from city road tunnels in the Bialystok area in Poland, especially to determine the content of platinum group metals. Kurtenbach et al. (2001) demonstrated the heterogeneous formation of nitrous acid (HONO) on the walls of the Kiesberg highway tunnel in Wuppertal in Germany.

\section{METHODS}

The Mrázovka road tunnel is a component of the internal city ring in Prague and was chosen for the measurements of specific air pollution in this microenvironment. The Mrázovka tunnel is $1.260 \mathrm{~m}$ long with driving directions placed in separate tubes, each with two lanes. Traffic intensity in the tunnel part where the measurements were performed was in 201123.000 vehicles per 24 hours, of which $96 \%$ were passenger cars. Sampling and measuring devices were placed in the breakdown lane where there was enough space for manipulating the devices during the full operation of the tunnel.

Pollutants concentrations measurements were performed during one week sampling campaigns to characterize week variability, both in emission composition and traffic flow. Separate campaigns were performed in different seasons to characterize also seasonal variations, especially in relation to winter road maintenance.

Several devices were used for measurements dependent on the character of the monitored pollutant. Particulate matter concentrations in fractions $\mathrm{PM}_{2.5}$ and $\mathrm{PM}_{10}$ were determined discontinuously by gravimetric analysis on microbalances MX5 (Mettler-Toledo GmbH, Switzerland) after their capturing on nitrocellulose filters in 24 hour intervals by using middle volume samplers Leckel MVS6 (Sven Leckel Ingenierbüro GmbH, Germany). EnvironCheck 107 (Grimm Aerosol Technik GmbH \& Co. KG, Germany) operating in continuous mode of measuring with $1 \mathrm{~min}$. intervals of data logging was used for particle size distribution in fractions $\mathrm{PM}_{1.0}, \mathrm{PM}_{2.5}$ and $\mathrm{PM}_{10}$. Concentrations of gaseous pollutants particularly $\mathrm{O}_{3}$, $\mathrm{NO}_{2}, \mathrm{NO}, \mathrm{NO}_{\mathrm{x}}, \mathrm{CO}, \mathrm{CO}_{2}, \mathrm{SO}_{2}$ and $\mathrm{H}_{2} \mathrm{~S}$ were measured continuously by the compact air quality monitoring system Airpointer (Recordum Messtechnik GmbH, Austria) with 1 min. intervals of data logging, except for $\mathrm{SO}_{2}$ and $\mathrm{H}_{2} \mathrm{~S}$ which had 5 min. intervals of data logging. 
Data evaluation and assessment was performed by using statistical software QC Expert (TriloByte, Czech Republic), NCSS (NCSS LLC USA) and R (The R Foundation for Statistical Computing, Austria).

\section{RESULTS AND DISCUSSION}

Mean week concentrations of measured pollutants summarized in Table 1 show differences between separate sampling campaigns. The small sample size of the dataset was the reason for the use of pivot half sum for mean of $\mathrm{PM}_{10}$ and $\mathrm{PM}_{2.5}$ concentrations, means of the other parameter was calculated as pivot half sums (Horn, 1983).

Table 1: Means week concentrations of measured pollutants and other parameters.

\begin{tabular}{|c|c|c|c|}
\hline \multirow{2}{*}{ Pollutant / Parameter } & \multicolumn{2}{|c|}{ Measurement duration } & \multirow{2}{*}{ Unit } \\
\hline & 7. - 13. 12. 2011 & 6. - 12. 6. 2012 & \\
\hline $\mathrm{O}_{3}$ & 5.98 & 2.92 & \multirow{4}{*}{$\mu \mathrm{g} \cdot \mathrm{m}^{-3}$} \\
\hline $\mathrm{NO}_{2}$ & 146.7 & 174.3 & \\
\hline NO & 442.2 & 378.0 & \\
\hline $\mathrm{NO}_{\mathrm{x}}$ & 824.6 & 753.3 & \\
\hline $\mathrm{CO}$ & 4.65 & 5.19 & \multirow{2}{*}{$\mathrm{mg} \cdot \mathrm{m}^{-3}$} \\
\hline $\mathrm{CO}_{2}$ & 764.3 & 777.4 & \\
\hline $\mathrm{SO}_{2}$ & 6.79 & 3.09 & \multirow{4}{*}{$\mu \mathrm{g} \cdot \mathrm{m}^{-3}$} \\
\hline $\mathrm{H}_{2} \mathrm{~S}$ & 4.13 & 3.85 & \\
\hline $\mathrm{PM}_{2.5}$ & 66.6 & 74.9 & \\
\hline $\mathrm{PM}_{10}$ & 175.1 & 149.3 & \\
\hline Temperature & 10.1 & 21.1 & ${ }^{\circ} \mathrm{C}$ \\
\hline Humidity & 46.8 & 50.7 & $\%$ \\
\hline No. of cars & 107356 & 162297 & veh. / week \\
\hline
\end{tabular}

Ozone concentration was nearly two times higher in the first sampling campaign. The total concentration of nitrogen oxides was also higher in the first sampling campaign as the nitrogen monoxide concentration was higher although the traffic intensity was higher in the second sampling campaign. On the other hand, the nitrogen dioxide concentration was higher in the second sampling campaign which corresponds to higher traffic intensity. The lower concentration of nitrogen monoxide in the second sampling campaign could be caused by its faster conversion to nitrogen dioxide due to higher temperatures and humidity in the tunnel environment. A possible explanation is also the faster decay of nitrogen oxides due to heterogeneous formation of nitrous acid (HONO) and nitric acid $\left(\mathrm{HNO}_{3}\right)$ on the tunnel walls or with the reaction of nitrogen oxides with air humidity in the presence of heated soot particles, although this process was described rather for the reaction of $\mathrm{NO}_{2}$ (Kurtenbach et al., 2001). In the second campaign, it also corresponds to a lower ozone content. Concentrations of carbon dioxide and carbon monoxide were somewhat higher in the second sampling campaign reflecting higher traffic intensity 
associated with higher carbon oxides emissions. $\mathrm{H}_{2} \mathrm{~S}$ and $\mathrm{SO}_{2}$ concentrations were higher in first campaign, as in the case of $\mathrm{NO}_{\mathrm{x}}$. Both $\mathrm{PM}_{10}$ and $\mathrm{PM}_{10}$ concentrations differences between the $1^{\text {st }}$ and $2^{\text {nd }}$ campaigns respectively were not statistically significant.

All differences between the concentrations of pollutants and other parameters except for PM were statistically significant (see Table 2) on level alpha $=0.05$ (i.e. with $95 \%$ probability variances are different from zero), as no confidence interval (CI) except for PM contains zero. The small sample size of dataset was the reason for the use of a pivot half sum for the means of $\mathrm{PM}_{10}$ and $\mathrm{PM}_{2.5}$ concentrations differences.

Table 2: 95\% CI of medians and pivot half sums ( $\left.{ }^{*}\right)$ of differences between concentrations of measured pollutants and other parameters in $2^{\text {nd }}$ and $1^{\text {st }}$ campaign (units are the same as in Table 1).

\begin{tabular}{|c|c|c|c|}
\hline $\begin{array}{c}\text { Difference: } \mathbf{2}^{\text {nd }} \mathbf{- 1}^{\text {st }} \\
\text { campaign }\end{array}$ & Mean & CI Lower Bound & CI Upper Bound \\
\hline D_O3 & -2.94 & -3.02 & -2.85 \\
\hline D_NO2 & 24.4 & 23.2 & 25.6 \\
\hline D_NO & -62.3 & -66.6 & -58.0 \\
\hline D_NOx & -68.0 & -75.0 & -61.0 \\
\hline D_CO & 0.682 & 0.664 & 0.701 \\
\hline D_CO 2 & 8.11 & 6.39 & 9.82 \\
\hline D_SO2 & -3.54 & -3.63 & -3.44 \\
\hline D_H $2 S$ & -0.154 & -0.207 & -0.100 \\
\hline D_PM ${ }^{*}$ & -19.9 & -62.1 & 22.3 \\
\hline D_PM ${ }^{*}{ }^{*}$ & 8.23 & $-11-5$ & 28.0 \\
\hline D_T & 10.8 & 10.7 & 10.9 \\
\hline D_RH & 6.30 & 6.00 & 6.60 \\
\hline
\end{tabular}

The concentrations of all measured pollutants were typically changed in between local minimal values and local maximum values in relation to daytime, or traffic volume, respectively. These values correspond to night time resp. day time. No more than 10 cars in a five minute interval passed through the tunnel part at night while the highest traffic intensity (from 30 up to 120 cars in five minutes interval) was between 6:45 to 10:00 AM.

The following graphs present the trends of one hour mean concentrations of separate pollutants within both sampling periods. Figure 1 presents the trends of nitrogen oxides concentrations. The minimum values of these pollutants concentrations were identified in both campaigns between Saturday midnight and 5 AM on Sunday morning. These very low concentrations compared to others correspond to the lowest traffic intensity during the whole campaign. Only 8 vehicles passed through the tunnel section during the period from Saturday midnight (10.12.2011) to Sunday morning 5 AM (11.12.2012). In general, nitrogen oxides concentrations were lower during weekend days when compared to working days. The highest concentrations were measured in both campaigns on Monday and Tuesday when $\mathrm{NO}_{\mathrm{x}}$ concentrations achieved a range between $1520 \mu \mathrm{g} \cdot \mathrm{m}^{-3}$ and $900 \mu \mathrm{g} \cdot \mathrm{m}^{-3}$. 
Similar trends were also identified for sulfur compounds $\left(\mathrm{SO}_{2}\right.$ a $\left.\mathrm{H}_{2} \mathrm{~S}\right)$ in the $1^{\text {st }}$ campaign with the minimal concentrations between Saturday midnight and 5 AM on Sunday morning and maximum concentrations on Monday and Tuesday (Figure 2). More significant variations of concentrations were measured during the $2^{\text {nd }}$ campaign but it was also possible to determine the minimum values in the same time period.
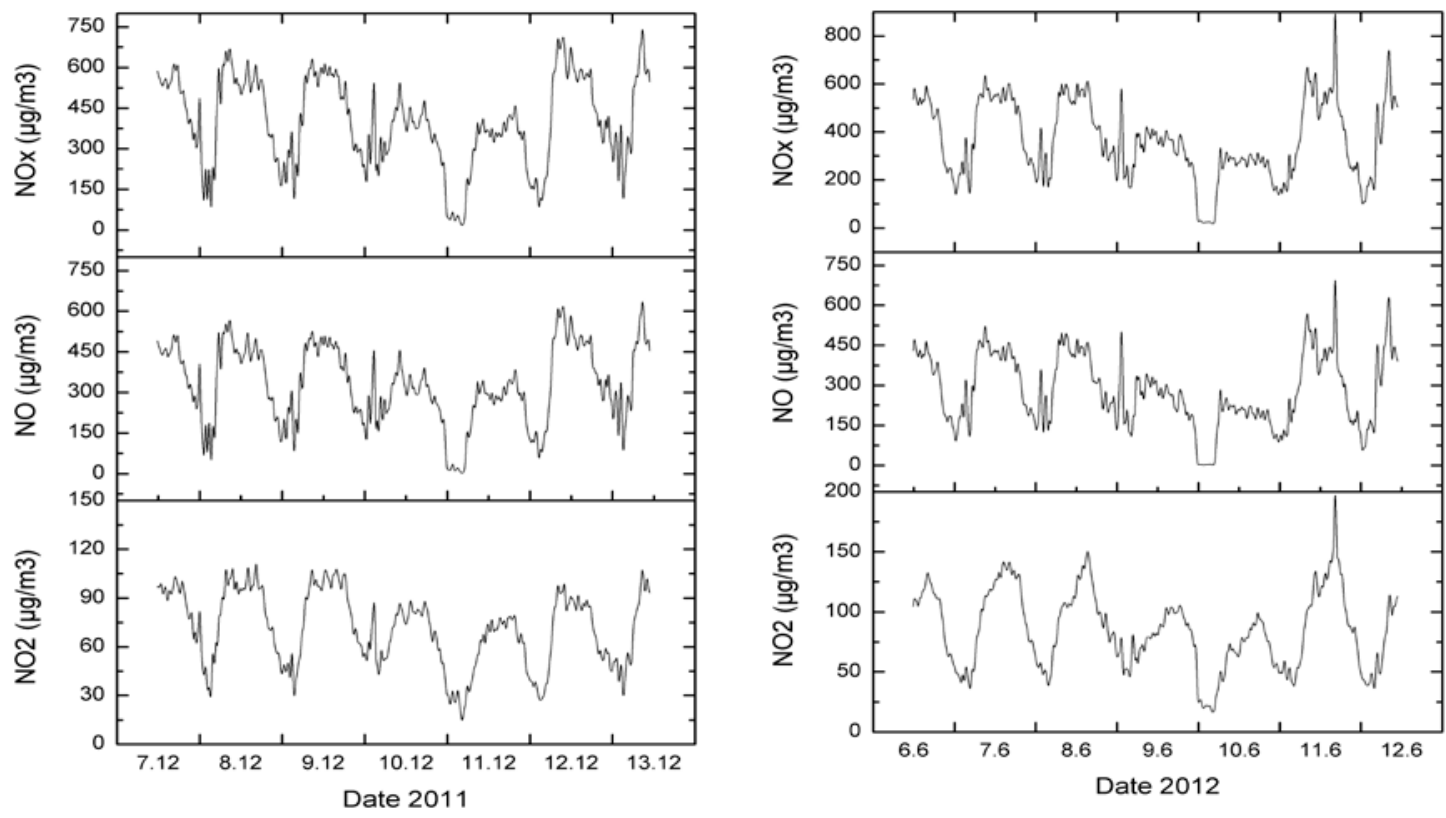

Figure 1: Nitrogen oxides concentrations progress $\left(1^{\text {st }}\right.$ sampling campaign on the left, $2^{\text {nd }}$ sampling campaign on the right graph).
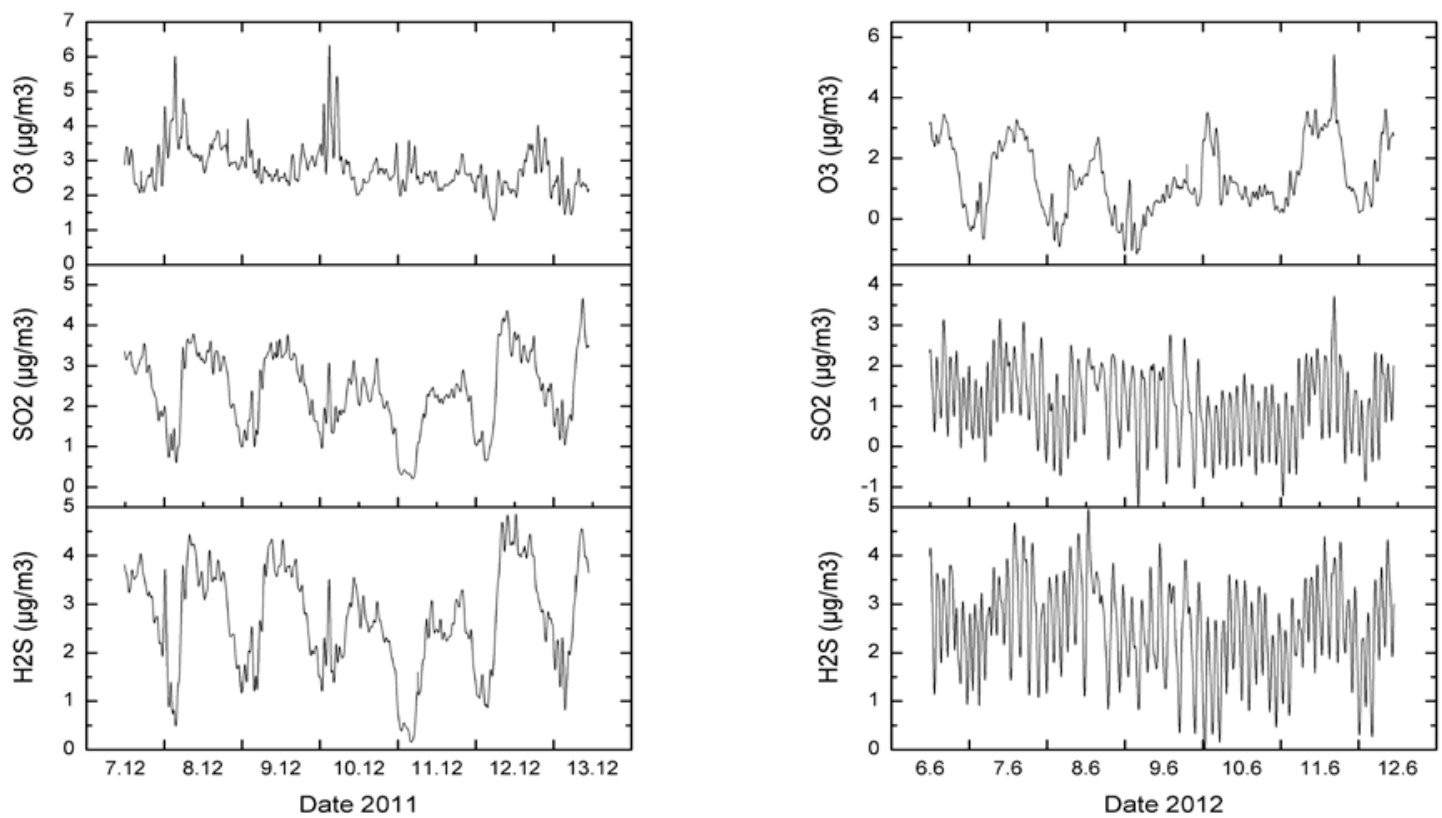

Figure 2: Sulphur dioxide, hydrogen sulphide and ozone concentrations progress $\left(1^{\text {st }}\right.$ sampling campaign on the left, $2^{\text {nd }}$ sampling campaign on the right graph). 

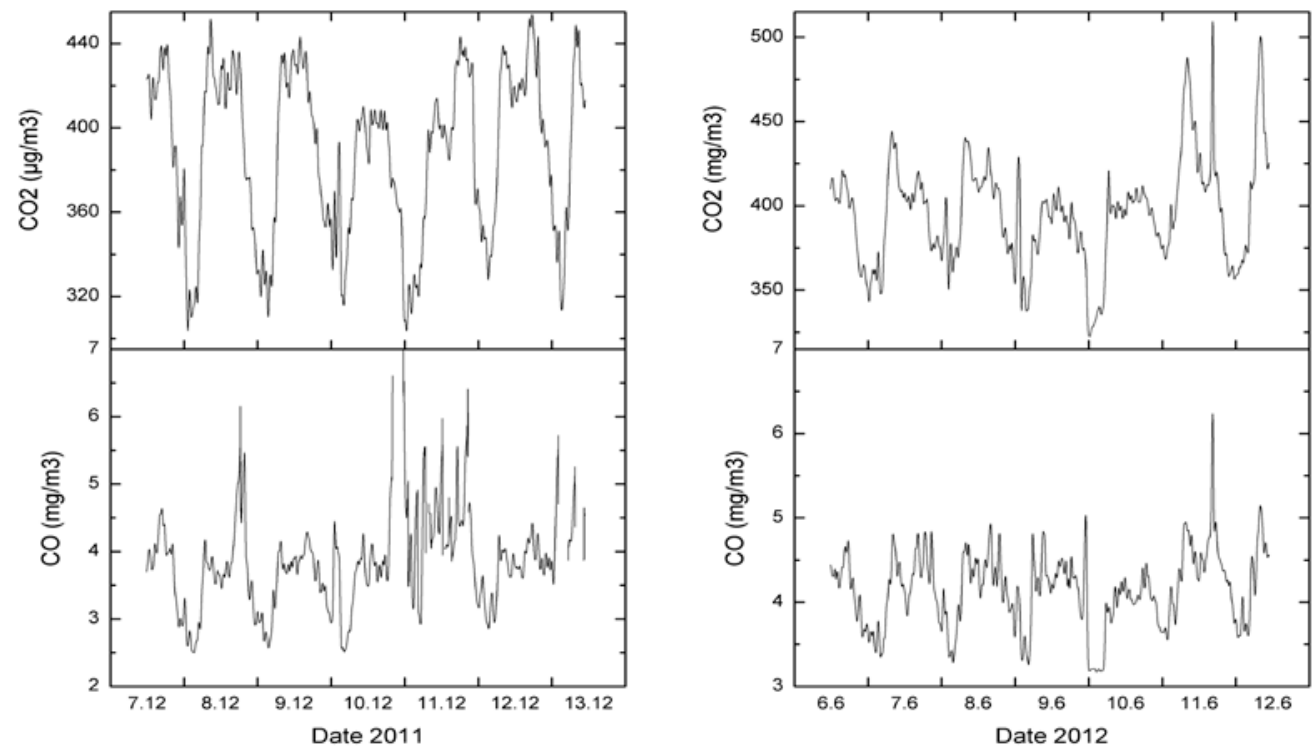

Figure 3: Carbon oxides concentrations progress $\left(1^{\text {st }}\right.$ sampling campaign on the left, $2^{\text {nd }}$ sampling campaign on the right graph).

Similar trends were also determined for carbon oxides with the minimal concentrations between Saturday midnight and 5 AM on Sunday morning and maximum concentrations on Monday and Tuesday (Figure 3). However, there was a significant difference between the separate campaigns since the concentrations in the $2^{\text {nd }}$ campaign were somewhat higher.

The following graphs in (Figure 4) present the continual measurements of particles size distribution. In general, particle size distribution showed in both campaigns a dominant share of coarse PM fraction $\mathrm{PM}_{2.5-10}$ but also a very high fluctuation over time. The highest share of coarse fraction was determined during the time of rush hour in the morning; on the other hand the lowest share was during the night time. These high shares of coarse PM fractions during rush hours could be caused by the resuspension of road dust from the road surface or its proximity due to the movement of a higher number of vehicles. Smaller differences were determined for fine particulate matter fraction $\left(\mathrm{PM}_{2.5}\right.$ and smaller) that are produced mostly by fuel combustion in vehicle engines. Nevertheless, the graphs showed higher concentrations of this particle fraction also during the rush hours.
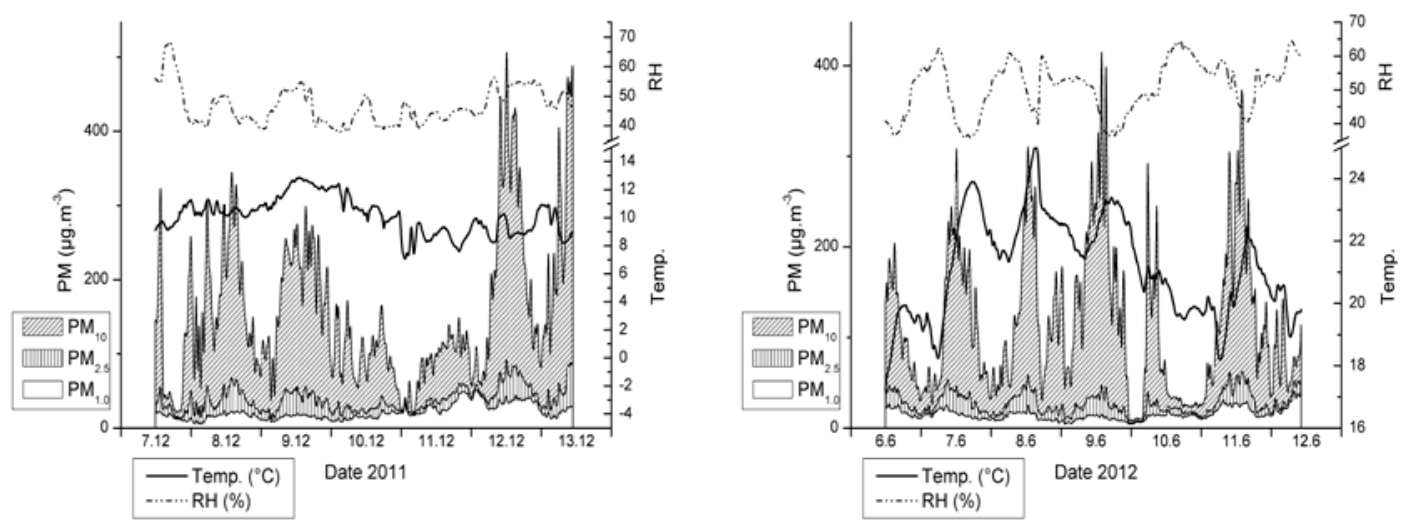

Figure 4: Particle size distribution $\left(1^{\text {st }}\right.$ sampling campaign on the left, $2^{\text {nd }}$ sampling campaign on the right graph). 
Measured $\mathrm{PM}_{10}$ concentrations were in very good agreement with the measurements in the road tunnel with nearly the same traffic intensity in Taiwan (Ma et al., 2011) and were slightly higher than in the road tunnel in Vienna (Laschober et al., 2004). $\mathrm{PM}_{2.5}$ concentrations were in accordance with those measured in the road tunnel in Antwerp (Worobiec et al., 2011). On the other hand, concentrations of $\mathrm{CO}$ and $\mathrm{NO}_{\mathrm{x}}$ were in this presented study 15 times lower compared to concentrations in the road tunnel in New York City (Lonneman et al., 1986). Such a big difference is probably either due to nearly 5 times higher traffic intensity or due to the worse quality of fuel in the 80 's and different types of engines with higher emissions of pollutants. The same causes could be the reason for nearly four times lower fine particles concentrations than those measured in 1993 in a freeway tunnel near Zürich (Weingartner et al., 1997). Nevertheless, the measured $\mathrm{CO}, \mathrm{SO} 2$ and $\mathrm{NO}_{\mathrm{x}}$ concentrations in the road tunnel Mrázovka are also nearly an order of magnitude lower compared to concentrations of gasses in the road tunnel in Taiwan (Ma et al., 2011) with nearly the same traffic intensity. However, the dominant compound in $\mathrm{NO}_{\mathrm{x}}$ is $\mathrm{NO}$ in both studies. Chow and Chen (2003) measured $\mathrm{CO}$ and $\mathrm{NO}_{2}$ concentrations in 11 road tunnels in Hong Kong and adjacent areas. The measured concentrations (ranging between $7.5 \mu \mathrm{g} . \mathrm{m}^{-3}$ and $50 \mu \mathrm{g} \cdot \mathrm{m}^{-3}$ for $\mathrm{CO}$ and between $657 \mu \mathrm{g} . \mathrm{m}^{-3}$ and $1561 \mu \mathrm{g} . \mathrm{m}^{-3}$ for $\mathrm{NO}_{2}$ ) were higher, but this comparison could be questionable because of the different methodology used for concentrations measurements since concentrations were measured in passing vehicle with opened windows.

\section{CONCLUSIONS}

All differences between mean concentrations in both the $1^{\text {st }}$ and $2^{\text {nd }}$ campaigns except for PM were statistically significant. The total concentration of nitrogen oxides was higher in the first sampling campaign although the traffic intensity was higher in the second sampling campaign. On the other hand, nitrogen dioxide concentration was higher in the second sampling campaign which corresponds to the higher traffic intensity. The lower concentration of nitrogen oxide in the second sampling campaign could have been caused by its faster conversion to nitrogen dioxide due to higher temperatures and humidity in the tunnel environment. Another possible explanation is also the faster decay of nitrogen oxides due to heterogeneous formation of nitrous acid (HONO) and nitric acid $\left(\mathrm{HNO}_{3}\right)$ on the tunnel walls or by the reaction of nitrogen oxides with air humidity in the presence of heated soot particles.

$\mathrm{H}_{2} \mathrm{~S}$ and $\mathrm{SO}_{2}$ concentrations were somewhat lower in the $2^{\text {nd }}$ campaign, probably due to faster oxidation due to the higher temperature, similarly to the case of nitrogen oxides.

The concentrations of all measured pollutants were typically changed in between local minimal values and local maximum values in relation to daytime, or traffic volume, respectively. These values correspond to night time resp. day time.

Particle size distribution in both campaigns showed a dominant share of coarse PM fraction $\mathrm{PM}_{2.5-10}$ but also a very high fluctuation over time. The highest share of coarse fraction was determined in the time of rush hour in the morning, on the other hand the lowest share was during the night. These high shares of coarse PM fractions during rush hours could be caused by resuspension of road dust from the road surface or its proximity due to the movement of a higher number of vehicles.

Data with pollutants concentrations and the ratios between them are being used to define conditions in accelerated degradation tests of several materials under laboratory conditions. 


\section{ACKNOWLEDGEMENTS}

The study was supported by the Technology Agency of the Czech Republic as the project No TA01031043 "Quantification of specific pollution effect on materials and corrosion protection in tunnels" and by the internal grant of CDV.

\section{REFERENCES}

Barrefors, G., 1996. Air pollutants in road tunnels. The Science of the Total Environment, 189/190, pp. 431-435.

Colberg, C.A., Tona, B., Stahel, W.A., Sturm, P., Meier, M., Staehelin, J., 2005. Comparison of a road traffic emission model (HBEFA) with emissions derived from measurements in the Gubrist road tunnel, Switzerland. Atmospheric Environment, 39 (26), pp. 47034714.

Gouriou, F., Morin, J.-P., Weill, M.-E., 2004. On-road measurements of particle number concentrations and size distributions in urban and tunnel environments. Atmospheric Environment, 38 (18), pp. 2831-2840.

Grieshop, A.P., Lipsky, E. M., Pekney, N.J., Takahama, S., Robinson, A.L., 2006. Fine particle emission factors from vehicles in a highway tunnel: Effects of fleet composition and season. Atmospheric Environment, 40, pp. S287-S298.

Handler, M., Puls, C., Zbiral, J., Marr, I., Puxbaum, H., Limbeck, A., 2008. Size and composition of particulate emissions from motor vehicles in the KaisermühlenTunnel, Vienna. Atmospheric Environment, 42 (9), pp. 2173-2186.

Hausberger, S., Rodler, J., Sturm, P., Rexeis, M., 2003. Emission factors for heavy-duty vehicles and validation by tunnel measurements. Atmospheric Environment, 37 (37), pp 5237-5245.

He, L.-Y., Hu, M., Huang, X.-F., Zhang, Y.-H., Yu, B.-D., Liu, D.-X., 2006. Chemical characterization of fine particles from on-road vehicles in the Wutong tunnel in Shenzhen, China. Chemosphere, 62 (10), pp. 1565-1573.

Ho, K.F., Sai Hang Ho, S., Lee, S.C., Cheng, Y., Chow, J. C., Watson, J. G., Louie, P.K.K., Tian, L., 2009. Emissions of gas- and particle-phase polycyclic aromatic hydrocarbons (PAHs) in the Shing Mun Tunnel, Hong Kong. Atmospheric Environment, 43 (40), pp. 6343-6351.

Horn, J., 1983. Some easy T-statistics. Journal of the American Statistical Association, 78 (348), p. 930.

Chow, W.K., Chan, M.Y., 2003. Field Measurement on Transient Carbon Monoxide Levels in Vehicular Tunnels. Building Environment, 38 (2), pp. 227-236.

Kristensson, A., Johansson, C., Westerholm, R., Swietlicki, E., Gidhagen, L., Wideqvist, U., Vesely, V., 2004. Real-world traffic emission factors of gases and particles measured in a road tunnel in Stockholm, Sweden. Atmospheric Environment, 38 (5), pp. 657-673. 
Kurtenbach, R., Becker, K.H., Gomes, J.A.G., Kleffmann, J., Lörzer, J.C., Spittler, M., Wiesen, P., Ackermann, R., Geyer, A., Platt, U., 2001. Investigations of emissions and heterogeneous formation of $\mathrm{HONO}$ in a road traffic tunnel. Atmospheric Environment, 35 (20), pp. 3385-3394.

Laschober, C., Limbeck, A., Rendl, J., Puxbaum, H., 2004. Particulate emissions from onroad vehicles in the Kaisermühlen-tunnel (Vienna, Austria). Atmospheric Environment, 38 (14), pp. 2187-2195.

Lésniewska, B.A., Godlewska-Zylkiewicz, B., Bocca, B., Caimi, S., Caroli, S., Hulanicki, A., 2004. Platinum, palladium and rhodium content in road dust, tunnel dust and common grass in Bialystok area (Poland): a pilot study. Science of the Total Environment, 321 (1-3), pp. 93-104.

Lonneman, W.A., Selia, R.L., Meeks, S.A., 1986. Nonmethane Organic Composition in the Lincoln Tunnel. Environmental Science and Technology, 20 (8), pp. 790-799.

Ma, C.M., Hong, G.B., Chang, C.T., 2011. Influence of Traffic Flow Patterns on Air Quality inside the Longest Tunnel in Asia. Aerosol and Air Quality Research, 11 (1), pp. 44-50.

McGaughey, G.R., Desaia, N.R., Allen, D.T., Seila, R.L., Lonneman, W.A., Fraser, M.P., Harley, R.A., Pollack, A.K., Ivy, J.M., Price, J.H., 2004. Analysis of motor vehicle emissions in a Houston tunnel during the Texas Air Quality Study 2000. Atmospheric Environment, 38 (20), pp. 3363-3372.

Oliveira, C., Martins, N., Tavares, J., Pio, C., Cerqueira, M., Matos, M., Silva, H., Oliveira, C., Camões, F., 2011 Size distribution of polycyclic aromatic hydrocarbons in a roadway tunnel in Lisbon, Portugal. Chemosphere, 83 (11), pp. 1588-1596.

Sanchez-Ccoyllo, O.R., Ynoue, R.Y., Martins, L.D., Astolfo, R., Miranda, R.M., Freitas, E.D., Borges, A.S., Fornaro, A., Freitas, H., Moreira, A., Andrade, M.F., 2009. Vehicular particulate matter emissions in road tunnels in Sao Paulo, Brazil. Environmental Monitoring and Assessment, 149 (1-4), pp. 241-249.

Song, Z., You, M., Duzgoren-Aydin, N.S., 2005. Characterization of particulate organics accumulated on the ceiling of vehicular tunnels in Hong Kong and Guangzhou, China. Atmospheric Environment, 39, pp. 6398-6408.

Valiulis, D., Čeburnis, D., Šakalys, J., Kvietkus, K., 2002. Estimation of atmospheric trace metal emissions in Vilnius City, Lithuania, using vertical concentration gradient and road tunnel measurement data. Atmospheric Environment, 36 (39 - 40), pp. 6001-6014.

Velíšek, J., 2010. Stanovení charakteru znečištění z dopravy. Ochrana ovzduší, (1), pp. 21-26. ISSN 1211-0337. (in Czech)

Weingartner, E., Keller, C., Stahel, W.A., Burtscher, H., Baltenspergert, A., 1997. Aerosol emission in a road tunnel. Atmospheric Environment, 31 (3), pp. 451-462. 
Worobiec, A, Darchuk, L., Krupinska, B., Rotondo, G.G., De Laet, H., De Backer, W., Van Grieken, R., 2011. Characterization of particulate matter in fractions PM1, PM2.5 - case study in Craeybeckx traffic tunnel, Antwerp, Belgium. In Pollution and Environment Treatment of Air, Prague (Czech Republic), May 17 - 20, 2011 [CD-ROM]. Prague (Czech Republic): Odour s.r.o. ISBN 978-80-02-02293-0.

The article was produced under the support of the project Transport R\&D Centre (CZ.1.05/2.1.00/03.0064) 